\title{
Intraruminal injection of urea and changes in secretion of parotid saliva in sheep
}

\author{
BY Y. OBARA AND K. SHIMBAYASHI \\ National Institute of Animal Health, Yatabe, Tsukuba, Ibaraki 300-2I, Japan
}

(Received 12 June 1978 - Accepted 15 May 1979)

\begin{abstract}
1. Sheep were injected with varying doses of urea into the rumen and changes in the amount of saliva secreted from one parotid gland were studied. When the dose of urea was $0.1-0.2 \mathrm{~g} / \mathrm{kg}$, the secretion underwent no change. When the dose was $0.3 \mathrm{~g} / \mathrm{kg}$, the secretion was inhibited. When the dose was 0.4 or $0.5 \mathrm{~g} / \mathrm{kg}$, there was a marked inhibition in the secretion.

2. There was a close relationship between the ammonia level of the jugular blood and the inhibition of salivary secretion. When the ammonia level exceeded approximately $0.28 \mathrm{mmol} / \mathrm{l}$, the secretion was inhibited abruptly.

3. Salivary secretion and rumen movement were inhibited when the blood ammonia level exceeded 0.28 $\mathrm{mmol} / \mathrm{l}$, after injection of ammonium acetate into the jugular vein.

4. Based on the results mentioned previously, the mechanism of inhibition on the secretion of parotid saliva is discussed in relation to the domestic ruminant in which urea had been injected into the rumen.
\end{abstract}

In the domestic ruminant a large amount of alkaline saliva of high buffering capacity is secreted to neutralize volatile fatty acids (VFAs) produced in the rumen. Moreover, the saliva contains urea, which enhances the activity of micro-organisms in the rumen. It is a characteristic of the domestic ruminant that urea present in the diet as non-protein nitrogen is converted into microbial protein, which can be utilized by the animal as a source of protein. When urea is administered to the animal in the diet, it is decomposed into ammonia by urease (EC 3.5. I .5) of rumen micro-organisms. When a large amount of urea is administered, an unusually large amount of ammonia is produced and the rumen $\mathrm{pH}$ increased. Salivary secretion is an important physiological function in the domestic ruminant. Nevertheless, only a few investigators have carried out studies on changes in salivary secretion induced by administration of urea to the ruminant. Wilson (196I) found that feeding urea had no effect on the amount or composition of the saliva secreted in sheep. Somers (I96I) administered urea in the diet of sheep and reported an increase in concentration of urea in the saliva but no change in the amount of salivary secretion. Oltjen et al. (I969) pointed out a remarkable decrease in the amount of flow of mixed saliva in cattle after the introduction of urea into the rumen and ascribed this to an increase in the ammonia concentration in the rumen, although they carried out no estimation of the blood ammonia concentration.

In the present experiments sheep were injected with varying doses of urea into the rumen and the effect of each dose on the secretion of parotid saliva was determined. Also, ammonium salts were injected directly into the jugular vein and changes in the secretion of parotid saliva and rumen movements observed. The results are discussed.

\section{EXPERIMENTAL}

Six female sheep weighing 30-39 kg were divided into two groups, which were used for Expts 1 and 2, respectively. They were subjected to a surgical operation to prepare a unilateral parotid fistula and a rumen fistula. The daily ration was composed of $300 \mathrm{~g}$ hay, 480 g concentrate (Obara \& Shimbayashi, 1975) and 50 g sodium bicarbonate, which was 

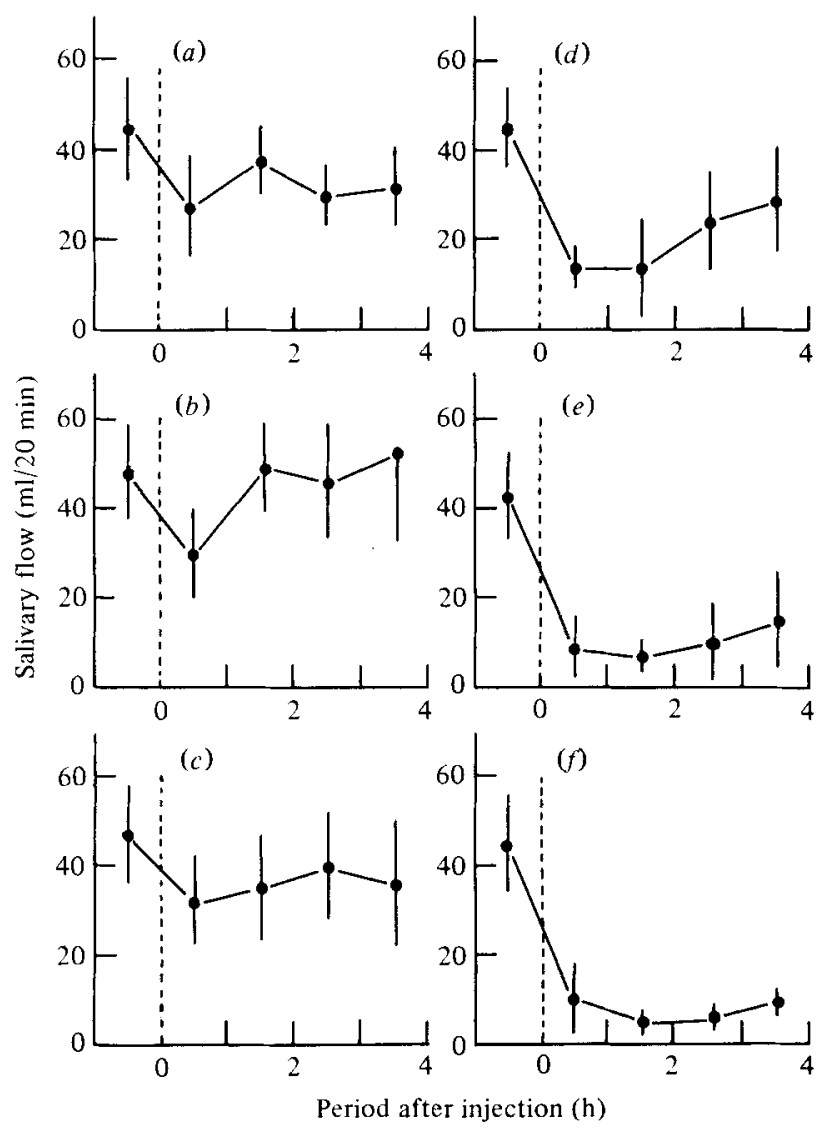

Fig. I. Expt 1. Changes iu salivary secretion $(\mathrm{ml} / 20 \mathrm{~min})$ from the unilateral parotid gland of sheep after intraruminal injection of urea doses $(\mathrm{g} / \mathrm{kg}):(a), 0 ;(b) 0.1 ;(c), 0.2 ;(d), 0.3 ;(e), 0.4 ;(f), 0.5$. Each point represents the mean value and standard deviations, represented by vertical bars, of the amounts of saliva measured in three sheep at 20 min intervals. Urea was injected into the rumen at o h (:). For details of procedures, see pp. 498-499.

sufficient to compensate for the loss of sodium in parotid saliva from the fistula. It was given at $\mathrm{I} 6.00$ hours. Each experiment was started $\mathrm{I} 6 \mathrm{~h}$ after feeding.

Expt $\mathrm{I}$. The intraruminal injection of urea. The amount of saliva secreted was determined over a period of $\mathrm{I} h$. After that, $50 \mathrm{ml}$ of an aqueous solution of urea containing $0,0 . \mathrm{I}, 0.2$, $0.3,0.4$ or $0.5 \mathrm{~g}$ urea $/ \mathrm{kg}$ body-weight was injected into the rumen through the fistula. Salivary secretion was measured at 20 min intervals over periods of $4 \mathrm{~h}$. A given dose was not administered until the influence of the preceding dose had disappeared completely. Samples of rumen contents and jugular blood were taken at given intervals and used for the estimation of ammonia concentration.

Expt 2. The injection of ammonium salts into the jugular vein. Before the beginning of this experiment a cannula was inserted into the jugular vein on each side, one for ammonia injection and the other for blood sampling. The amount of parotid saliva secreted was measured at 10 min intervals. It was also recorded simultaneously using a drop counter. Rumen movements were recorded electrically using a strain-gauge transducer connected to a balloon via a polyethylene tube. Salivary secretion and rumen movement were observed over a preliminary period of $\mathrm{I} h$. Then $3 \mathrm{M}$-ammonium acetate solution (corrected to $\mathrm{pH}$ 


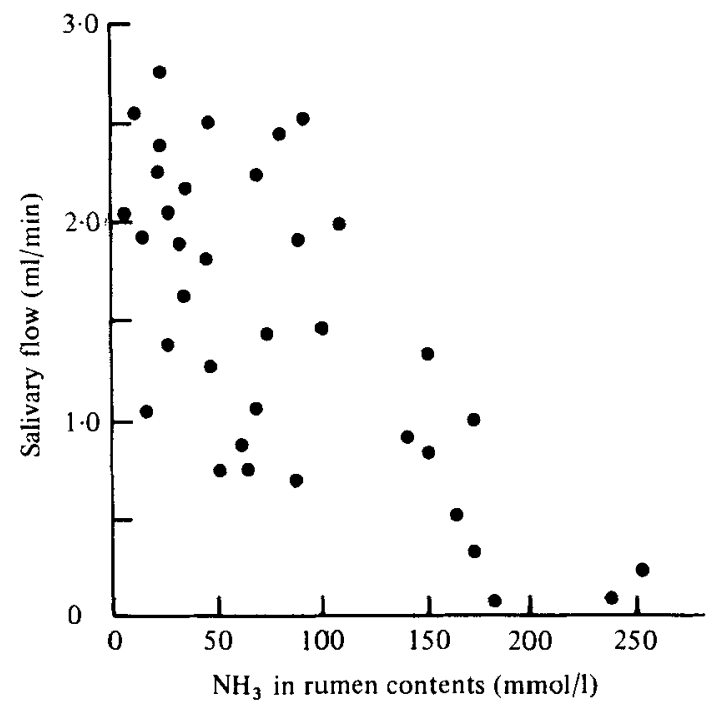

Fig. 2. Expt 1 . Relationship between the amount of salivary secretion $(\mathrm{ml} / \mathrm{min})$ and the ammonia concentration (mmol/l) of rumen contents of sheep after injection of urea into the rumen $(r-0.533$, $n 36 ; P<0.01$ ). For details of procedures, see pp. 498-499.

7.4) was injected into the jugular vein at varying velocities using a constant-velocity injecting instrument. Salivary secretion and rumen movement were observed at various ammonia levels in jugular blood between 0.18 and $0.74 \mathrm{mmol} / 1$. In a control experiment $3 \mathrm{M}$-sodium acetate (corrected to $\mathrm{pH} 7.4$ ) was injected into the jugular vein at a velocity of $0.78 \mathrm{mmol} / \mathrm{min}$. Blood samples were collected and the ammonia concentration estimated by colorimetry (Weatherburn, I967).

\section{RESULTS}

Expt 1. The intraruminal injection of urea. Fig. I shows changes in the amount of salivary secretion after intraruminal injection of urea and gives mean values and standard deviations for the amount of salivary secretion during a period of $\mathrm{I} \mathrm{h}$, measured at 20 min intervals in three sheep. As a control water was injected into the rumen and the amount of saliva secreted was almost constant, approximately $40 \mathrm{ml} / 20 \mathrm{~min}$. There were no significant changes in the amount of saliva secreted after 0.1 or $0.2 \mathrm{~g}$ urea $/ \mathrm{kg}$ was injected. When $0.3 \mathrm{~g}$ $\mathrm{urea} / \mathrm{kg}$ was injected, the salivary secretion tended to decrease for $\mathrm{I}-3 \mathrm{~h}$ after injection and then increase to the pre-injection level. Injection with $0.4 \mathrm{~g}$ urea $/ \mathrm{kg}$ inhibited salivary secretion to an even greater extent. After injection with $0.5 \mathrm{~g}$ urea $/ \mathrm{kg}$ the salivary secretion was markedly reduced up to the end of the experimental period. In brief, the greater the amount of urea injected, the more strongly the salivary secretion was inhibited. Rumen movement was studied by observing the movement of the rumen fistula over the experimental period. When there was a decrease in salivary secretion, the ruminal movement slowed and ceased.

To clarify the mechanism of inhibition of salivary secretion, studies were made of the relationship between the amount of saliva secreted and the ammonia concentration of the rumen contents and blood (Figs. 2 and 3 ). There was a negative correlation $(r-0.533$; $P<0.01$ ) between the amount of saliva secreted and the ammonia concentration of the rumen contents, a rather wide range of fluctuation being presented. There was a very high negative correlation $(r-0.889 ; P<0.01)$ between the amount of saliva secreted and the ammonia concentration of the jugular blood. Therefore, it was presumed that blood 


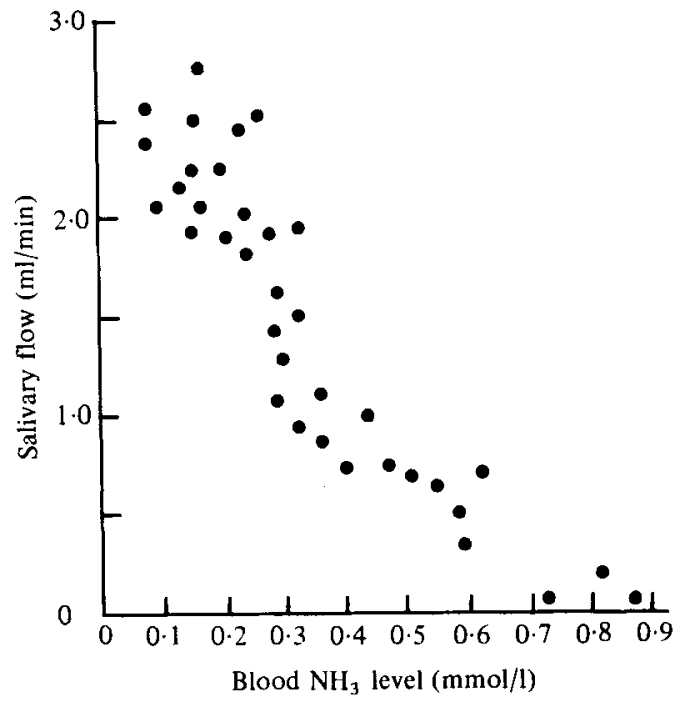

Fig. 3. Expt I. Relationship between the amount of salivary secretion $(\mathrm{ml} / \mathrm{min})$ and the ammonia concentration of jugular blood of sheep after injection of urea into the rumen $(r-0.889, n 36$; $P<0.01$ ). For details of procedures, see pp. 498-499.

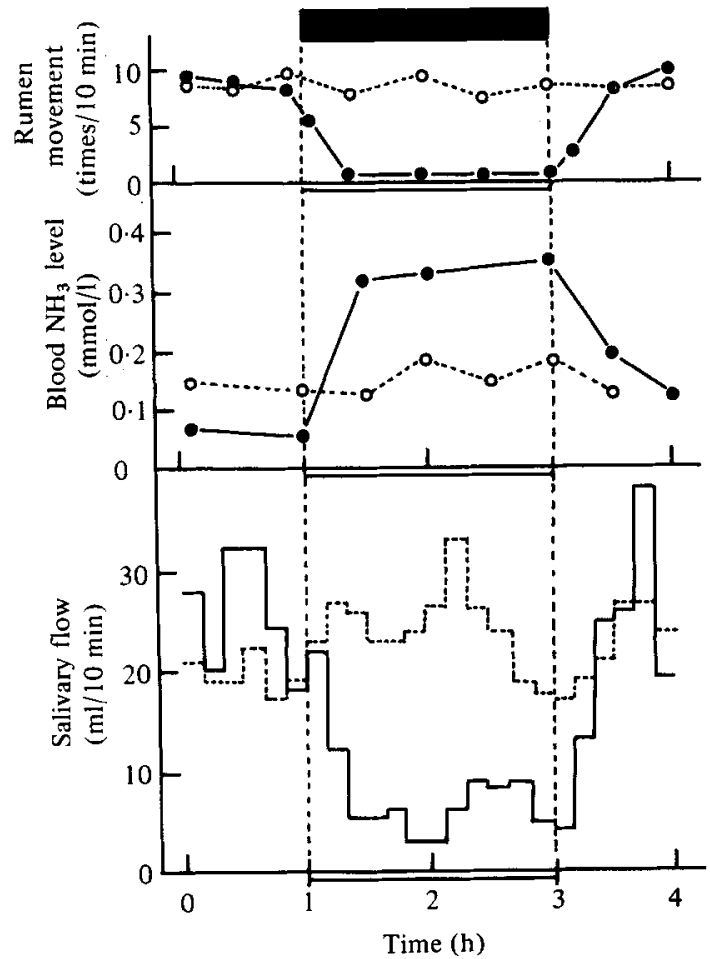

Fig. 4. Expt 2. Changes in blood ammonia level (mmol/l), rumen movement (times/10 min) and salivary secretion $(\mathrm{ml} / 10 \mathrm{~min})$ from unilateral parotid gland after consecutive injections of ammonium acetate at $0.98 \mathrm{mmol} / \mathrm{min}(\odot),(-)$ or sodium acetate (control) $(0),(-$,$) into the jugular$ vein of sheep. $(\neg)$, period of ammonium acetate or sodium acetate injection. 


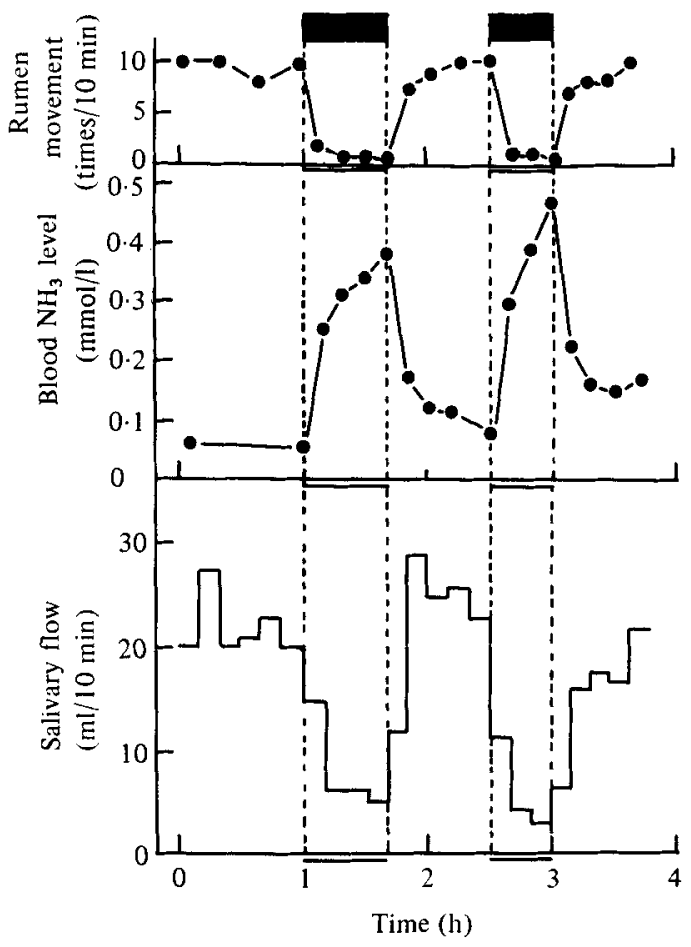

Fig. 5. Expt 2. Changes in blood ammonia level (mmol/l), rumen movement (times/Io min) and salivary secretion $(\mathrm{ml} / \mathrm{I}$ o min) from unilateral parotid gland after two consecutive injections with ammonium acetate at $0.98 \mathrm{mmol} / \mathrm{min}(-),(-)$ into the jugular vein of sheep. $(-)$, Period of ammonium acetate injection.

ammonia may play an important role in the inhibition of salivary secretion. It seemed that the salivary secretion may decrease rapidly in amount when the blood ammonia level exceeds approximately $0.28 \mathrm{mmol} / \mathrm{l}$.

Expt 2. The injection of ammonium salts into the jugular vein. Changes in salivary secretion and rumen movement were examined in sheep in which the blood ammonia level exceeded $0.28 \mathrm{mmol} / \mathrm{l}$ after injection of ammonium acetate into the jugular vein. In a control experiment sodium acetate was injected. The results obtained are shown in Fig. 4. In the control experiment the blood ammonia level was $0.13-0.18 \mathrm{mmol} / \mathrm{l}$ and the frequency of rumen movement eight to ten times/ro min. Salivary secretion tended to increase a little. When the blood ammonia level exceeded $0.28 \mathrm{mmol} / \mathrm{l}$ after injection of ammonium acetate, rumen movement disappeared completely and the amount of salivary secretion, which was $25 \mathrm{ml} / \mathrm{Io}$ min in the control experiment, was reduced to $10 \mathrm{ml}$ or less/10 min. When the blood ammonia level decreased to the pre-injection value after injection of ammonium acetate had stopped, salivary secretion and rumen movement returned to the pre-injection state.

Fig. 5 indicates changes in salivary secretion and rumen movement when the blood ammonia level was raised to $0.28-0.42 \mathrm{mmol} / 1$ twice by injection of ammonium acetate and when it was reduced to the pre-injection level by stopping injection. When the level exceeded $0.28 \mathrm{mmol} / \mathrm{l}$, salivary secretion and rumen movement were inhibited. When this level decreased to the pre-injection value after stopping the injection, salivary secretion and rumen movement returned to the pre-injection state.

Fig. 6 shows the pattern of rumen movement and the amount of salivary secretion, 
(a)

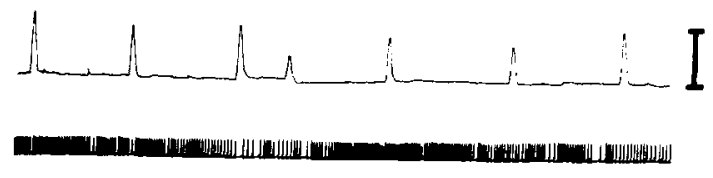

(b)

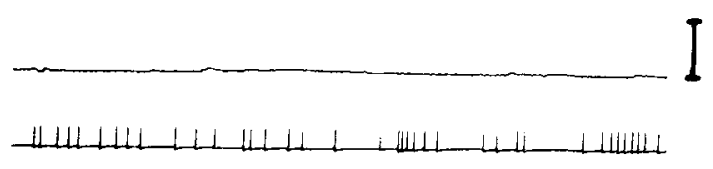

(c)

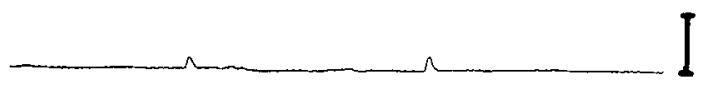

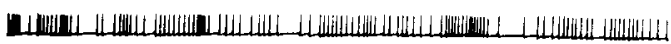

$(d)$

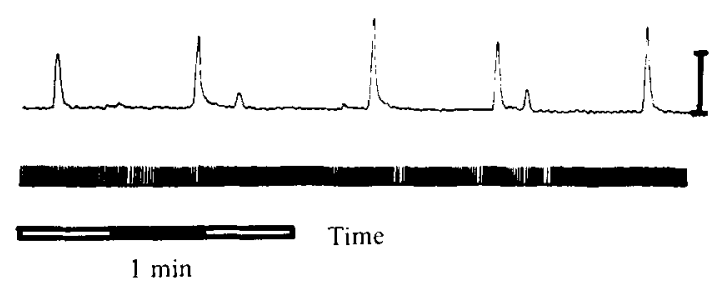

Fig. 6. Expt 2. Pattern of rumen movement (upper trace) and the number of drops of secreted saliva (lower trace) measured using a drop counter at varying blood ammonia levels after injection of ammonium acetate into the jugular vein of sheep. Vertical bars (I) represent amplitude of rumen movement, $100 \mathrm{~mm} \mathrm{H}_{2} \mathrm{O}$. (a) Control, $0.13 \mathrm{mmol} \mathrm{NH} / \mathrm{l} ;(b) 20 \mathrm{~min}$ after start of injection, 0.32 mmol $\mathrm{NH}_{3} / \mathrm{l} ;$ (c) $5 \mathrm{~min}$ after stopping of injection, $0.26 \mathrm{mmol} \mathrm{NH}_{3} / \mathrm{l} ;(d) 40 \mathrm{~min}$ after ending of injection $0.16 \mathrm{mmol} \mathrm{NH}_{3} / 1$. For details of procedures, see p. 502 .

measured using the drop counter, at varying blood ammonia levels. In the control experiment both salivary secretion and rumen movement were normal. When the blood ammonia level reached $0.32 \mathrm{mmol} / \mathrm{l}$ after injection of ammonium acetate, salivary secretion was inhibited distinctly and rumen movement stopped completely. At $5 \mathrm{~min}$ after stopping the injection of ammonium acetate the blood ammonia level reached $0.26 \mathrm{mmol} / \mathrm{l}$ and there were signs of rumen movement reappearing. There was a marked stimulation of salivary secretion and rumen movements increased in amplitude 40 min after ending the injection.

All the results obtained from three sheep were used to examine the correlations between the blood ammonia level, the frequency and amplitude of rumen movement, and the amount of salivary secretion. The results obtained are shown in Fig. 7. There were high correlations between the blood ammonia level and the frequency of rumen movement $(r-0.846)$ and also its amplitude $(r-0.770)$. There was a high negative correlation between blood ammonia levels and the amount of salivary secretion $(r-0.775)$. An increase in blood ammonia level inhibited secretion and rumen movement. This inhibitory effect was apparent when the ammonia level of the jugular blood reached approximately $0.28 \mathrm{mmol} / 1$, as was the situation in the animals given injections of urea into the rumen, although there was a small individual difference. 


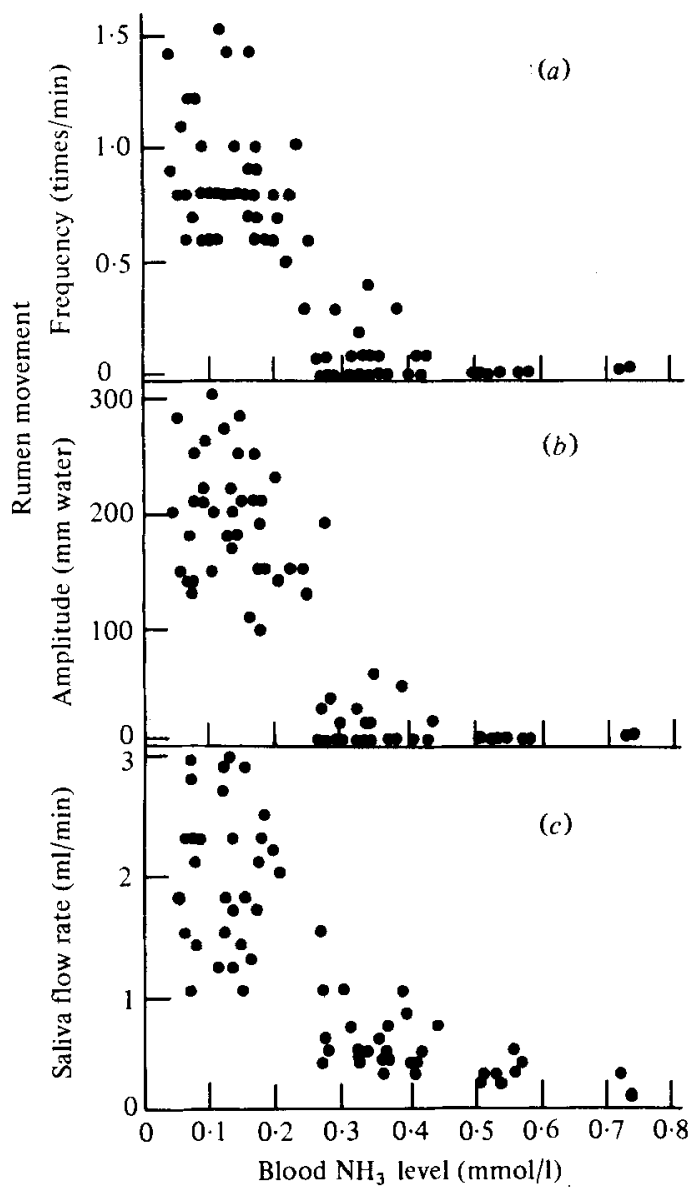

Fig. 7. Expt 2. Relationship between blood ammonia level ( $\mathrm{mmol} / \mathrm{l})$ and rumen movement $(a$, frequency (times/min); $b$, amplitude ( $\mathrm{mm}$ water)) or salivary secretion $(c)(\mathrm{ml} / \mathrm{min})$ after injection of ammonium acetate into the jugular vein of sheep. For details of procedures, see p. 502. $(a), r-0.846$, $P<0.01 ;(b), r-0.770, P<0.01 ;(c), r-0.775, P<0.01$.

\section{DISCUSSION}

There have been a few studies (Wilson, 1961; Somers, 196r; Oltjen et al. 1969) to determine changes in salivary secretion in domestic ruminants either given urea in the diet or administered urea into the rumen. The results obtained varied with feeding condition and with the dose and method of administration of urea and indicated no factor exerting influence on the amount of salivary secretion. Therefore, the urea dose was varied to clarify the relationship between salivary secretion and the extent of ammonia production in the rumen in the present experiment. When 0.1 or $0.2 \mathrm{~g}$ urea $/ \mathrm{kg}$ was injected into the rumen, there was no change in the amount of saliva secreted. When $0.3 \mathrm{~g}$ urea $/ \mathrm{kg}$ was administered, the salivary secretion tended to decrease. When 0.4 or $0.5 \mathrm{~g}$ urea $/ \mathrm{kg}$ was administered, there was a marked inhibition of salivary secretion. In short, the greater the dose of urea administered into the rumen, the greater the extent of inhibition of salivary secretion. Huber et al. (1967) reported that when non-protein $\mathrm{N}$ was administered, a minimum dose of $0.45 \mathrm{~g} / \mathrm{kg}$ caused a decrease in milk yield and food intake in cattle. It is of interest to note that the same dose inhibited salivary secretion in the present experiment. 
There was a negative correlation between the amount of saliva and the ammonia concentration in both rumen contents and blood. A particularly high correlation coefficient was found between the amount of salivary secretion and the ammonia concentration of the jugular blood. It was concluded that salivary secretion was reduced in accordance with an increase in the ammonia concentration of the jugular blood. In particular, salivary secretion was inhibited suddenly when the ammonia concentration in jugular blood exceeded 0.28 $\mathrm{mmol} / \mathrm{l}$. It has never been reported before that the secretion of saliva from the parotid gland is inhibited in sheep when the ammonia concentration in the jugular blood exceeds 0.28 $\mathrm{mmol} / \mathrm{l}$. Lewis et al. (I957) reported that so long as the ammonia concentration of the rumen contents was less than $60 \mathrm{mmol} / \mathrm{l}$, there was no increase in the ammonia concentration of the peripheral blood, since the absorbed ammonia was decomposed in the liver. They also mentioned that when that concentration exceeded $60 \mathrm{mmol} / \mathrm{l}$, there was an increase in the ammonia concentration of the peripheral blood in parallel with an increase in the ammonia concentration of the rumen contents. In the present experiment the rumen contents were not mixed satisfactorily because of the cessation of rumen movement, and the ammonia concentration of the rumen contents was reflected in that of the blood. Consequently, there seemed to be less correlation between the ammonia concentration of the rumen contents and the amount of salivary secretion.

To clarify the mechanism by which the secretion of saliva from the parotid gland was inhibited by intraruminal injection of urea, ammonia was injected directly into the blood to raise the blood ammonia level to $0.28 \mathrm{mmol} / \mathrm{l}$, and salivary secretion was monitored. Simultaneously, rumen movement was recorded to clarify the mechanism of inhibition of salivary secretion. There have been no reports of studies to elucidate changes in salivary secretion from the parotid gland after direct injection of an ammonia salt into the jugular vein. In the present experiment injection of ammonia salt into the jugular vein inhibited salivary secretion and rumen movement slowed down and eventually stopped when the blood ammonia level reached approximately $0.28 \mathrm{mmol} / 1$. Such inhibitory effect was enhanced when this level was further raised. There was a very high negative correlation between the ammonia level of the jugular blood and salivary secretion, as well as rumen movement. Recently, Itabisashi (1977) reported that in goats injected with urea into the rumen, as well as goats injected with ammonium acetate into the jugular vein, rumen movement disappeared when the blood ammonia level was within the range $0.28-0.58 \mathrm{mmol} / 1$. Bueno et al. (1977) reported that when ammonia was introduced into the rumen of sheep rumen contraction was inhibited, but hyperammonia induced by infusion into the jugular vein had no effect. In the present experiment with sheep, rumen movement disappeared when the blood ammonia level was within a range $0.28-0.43$ $\mathrm{mmol} / \mathrm{l}$. This result agreed quite well with that obtained in goats by Itabisashi ( 1977 ).

From the results of the present experiment discussion is made of the relationship between changes in properties of the rumen contents and salivary secretion from the parotid gland in domestic ruminants administered urea. In domestic ruminants the urea was changed into ammonia in the rumen by the action of the urease of intraruminal microbes. The ammonia was then converted into microbial protein, which could be utilized as protein by the ruminants. If a large dose of urea is administered and an excessive amount of ammonia produced, $\mathrm{pH}$ will rise and ammonia will be absorbed in the rumen. The amount of ammonia absorbed is so large that it cannot be metabolized totally in the liver. Some of it will overflow into the peripheral blood. It is possible that when the ammonia concentration in peripheral blood exceeds $0.28 \mathrm{mmol} / \mathrm{l}$, it will exert an inhibitory effect on the centre of salivary secretion.

Inhibition in salivary secretion from the parotid gland and rumen movement may be regarded as symptoms indicating the early stage of ammonia poisoning. It seems at least 
necessary to take care in the feeding and management of domestic ruminants not to allow the blood ammonia level to exceed $0.28 \mathrm{mmol} / \mathrm{l}$ when a urea diet is administered.

The authors wish to express their hearty thanks to Dr Tomoo Itabisashi of the National Institute of Animal Health for instruction in recording rumen movement. They also appreciate the help extended by Mr Hajime Matsumoto of the Azabu Veterinary College and Mr Hiroshi Sakae, Fuchu Hygiene Service Center, Prefecture of Hiroshima, for the completion of the second experiment of the present studies.

\section{REFERENCES}

Bueno, L., Doulou, V. \& Candau, M. (1977). Ann. Biol. anim. Bioch. Biophys. 17, 509.

Huber, J. T., Sandy, R. A., Polan, C. E., Bryant, H. T. \& Blaser, R. E. (1967). J. Dairy Sci. 50, 1241.

Itabisashi, T. (1977). Natn. Inst. Anim. Hlth. Q. 17, 128.

Lewis, D., Hill, K. J. \& Annison, E. F. (1957). Biochem, J. 66, 587.

Obara. Y. \& Shimbayashi, K. (1975). Jap. J. zootech. Sci. 46, I40.

Oltjen, R. R., Putnum, P. A. \& Williams, E. E., Jr (1969). J. Anim. Sci. 29, 830.

Somers, M. (I961). Aust. J. exp. Biol. Med. Sci. 39, I33.

Weatherburn, M. W. (1967). Analyt. Chem. 39, 971 .

Wilson, A. D. (1961). Nature, Lond. 192, 271. 